\title{
Examining Competencies of Entry-Level HR Professionals: Implications for Higher Education in HR
}

\author{
Putthachat Angnakoon ${ }^{1}$, Chih-Hung Chung ${ }^{2}$, Nicholas Evangelopoulos ${ }^{3}$ and Laura A. Pasquini ${ }^{4}$ \\ ${ }^{1}$ Faculty of Learning Sciences and Education,Thammasat University, Thailand \\ ${ }^{2}$ Department of Educational Technology, Tamkang University, Taiwan \\ ${ }^{3}$ Department of Information Technology \& Decision Science, University North Texas, U.S.A \\ ${ }^{4}$ Department of Learning Technology, University North Texas, U.S.A
}

\begin{abstract}
With the rapid advances in technology and globalization, people are faced with many challenges in the HR professions. Competencies of entry-level HR professionals also need to be surveyed, so that the gap could be decreased between higher education and practice. Therefore, the purpose of this study is to use the text mining technique to explore the competencies of entry-level human resource professionals through the use of Latent Semantic Analysis (LSA). Text mining-LSA is used to uncover and help understand the hidden trends and patterns from a mass dataset. Based on the results of this study, we found four major competencies (communication, skills, ability, and education) and thirteen sub factors (educational degree, communication, experience, leadership, office-software operation, teamwork relative education field, project management, presentation skills, analytical ability, certification, accepting traveling, and labor law knowledge) were proposed. The results could assist HR curriculum developers and HR educators in designing and tailoring their current curriculum to address the up-to-date competencies required for effective HR professionals. Hence, HR graduates are then best prepared for their jobs.
\end{abstract}

Keywords: Text mining, LSA, HR professional, entry-level

\section{Introduction}

The changing landscape of technology, the shortage of skilled labor, and the short shelf-life of knowledge are challenging organizations to rethink their approaches in developing and implementing effective policies and practices. Human resource (HR) professionals must be more than just training experts: they are required to remain aware of the trends and keep abreast of the fast changing world [1]. HR professionals are required to support organizations to foster business development, growth, and to keep up with the industries' challenges [2]. HR professionals must continually demonstrate and update the appropriate skills and competencies to meet this demand.

Universities have long been tasked with developing the skills and capabilities that current and future employees need to succeed within organizations. Program curricula follow organizational trends as academics maintain courses that are relevant and appropriate to support organizational needs [3]. The human resource profession has seen an increase in the number of universities that offer programs to develop HR professionals with necessary competencies to support organizations' changing needs. Six competency domains were identified in the Human Resource Competency Study (HRCS).

The purpose of this study is to observe the competencies of entry-level human resource professionals with Latent Semantic Analysis. Three hundred online job announcements of entry-level HR positions, including the fields of Human Resource Development (HRD) and Human Resource Management (HRM), from LinkedIn are collected and analyzed with the text mining (TM) technique, which is a technique used to uncover and recognize the hidden trends and patterns from a mass dataset. This technique helps to discover 
and extract valuable patterns, models, trends, or rules from an unstructured text dataset [4]-[6]. The results of our analysis suggest that entry-level job seekers in the HR field require four major competencies, practical experience, skills, abilities, and education. The authors also hope that the implications may assist HR curriculum developers and HR educators in designing and tailoring their current curriculum to address up-todate competencies required for effective HR professionals. Hence, HR graduates are then best prepared for their jobs.

\section{Literature Review}

\subsection{The Studies of Human Resource Development and Management Competency}

Depending on the field of reference, "competency" can be defined differently. Whereas psychologists may see it as the personal attributes, such as mental, attitudinal, or psychomotor, perceived as essential for a person to successfully perform a job, a HR manager may be interested in other aspects of personal characteristics. Boyatzis (1982) extended the definition of competency to include both internal and external constraints, environments, and relationships that have some association to a given job. Boyatzis (1982) define competency as "an underlying characteristic of an employee (e.g. motive, trait, skill, aspects of one's self-image, social role, or a body of knowledge) which results in effective and/or superior performance in a job" (1982, p.20). Spencer and Spencer define it similarly; competency is "an underlying characteristic of an individual that is causally related to criterion-referenced effective and/or superior performance in a job or situation" (1993, p.11). Brockbank and Ulrich have been tracking the changing HR competencies since 1988. Five sequential phases of the Human Resource Competency Study (HRCS) were carried out on large-scale surveys in 1988, 1992, 1997, 2002, and 2007, resulting in a large data set of competencies necessary for HR professionals. The 2007 HRCS study proposed six core competencies performed by effective HR professionals.

1) Credible Activist - HR professionals have effective personal skills which flexibly develop positive relationships with key stakeholders by consistent, clear, and insightful communication. Additionally, they present confidence in their opinions with business.

2) Strategic Positioner - HR professionals should understand and be familiar with the global business environment. They comprehend the business structure and their industries; moreover, they know the essential competition in the dynamic markets that they serve.

3) Capability Builder - HR professionals could build essential capabilities for adapting to dynamic markets.

4) Change Champion - They should advance their organization's capacity for change; in addition, they translate it into effective processes.

5) Human Resource Innovator and Integrator - HR professionals are both innovator and integrator. They generate creativity and integrate different professional human resources for improving the organization's performance.

6) Technology Proponent - Other than applying technology to the basic HR work, effective HR professionals adopt social-networking technology to support people to connect with each other. Moreover, they increase their roles in the management of information.

However, this might not be relevant to the current job market because of time change. Therefore, now, it would be good to re-examine and discover new trends in major competences for HR professionals.

\subsection{University HR Curriculum}

HRM is the management activities in any organizations where people are employed. HRM has three major subfields, including Micro HRM, Strategic HRM, and International HRM [7]. Micro HRM includes the HR policy and practice in such areas as recruitment, selection, induction, training and development, performance management, and remuneration [8]; Strategic HRM emphases on the HR strategies related with business units and organization; moreover, it attempts to evaluate their impact on performance [9]. Finally, International HRM focuses on cross-national HRM issues, such as cross cultural issues and operations across national boundaries [10], [11]. In MBA programs and business education, HRM have been broadly adopted. 
However, course grades and the degree from an MBA program has been argued that they have no relationship with the critical keys of career success [12]. The need for better-educated workers has been increased; thus, competency-based learning programs become more and more important [13]. Understanding what major qualifications in HRM fields in the real world is necessary to help designing and planning a suitable training program for HRM. Therefore, we presented our research question as follow:

RQ: What are the major qualifications in the HRM field in the HR job market?

\subsection{Job Ads as Research Data}

There are increasing numbers of studies, especially in information science fields, that use job advertisements as research data sets. The primary purpose of these studies is to examine change in skill requirements and to identify currency of skills in the workplace [14]. Many studies have used job advertisements as data sources to identify skills and competencies since the advertisements offer various sources of information on the main competencies. Gray (1999) determined types of competencies for HRD practitioners. Wenger and Owens (2012) identified the skills required for a candidate to be recruited and be successful in journalism professions. Hämäläinen, Porras, \& Ikonen (2011) determined types of skills and analyzed meaningful terms from ICT job advertisements using an automatic semantic-approach tool. Litecky, Aken, Ahmad, and Nelson (2010) employed a web content data mining application to identify job skills for computing professionals. Surakka (2005) identified technical skills required for software developer positions. The authors also examined trends of the skills required over a 15 -year period. In other words, advertisements contain adequate information for analyzing and extracting job competencies. Job advertisements contain an up-to-date set of skills that reflect not only the requirements set by the industry, but also current employment environments and development in the labor market [14], [17].

Nevertheless, some drawbacks of using job advertisements as research data have also been reported. Croneis and Henderson (2002) pointed out the limitations of internal advertisements, which make the advertisement inaccessible in the public. Another issue reported by Ahmed (2005) is that of ambiguous copy in the advertisement, which results in problematic coding and analysis due to lack of language precision.

\subsection{Text Mining Approach - Latent Semantic Analysis (LSA)}

Text mining techniques aim to discover and extract interesting information from semi-structured or unstructured data sets, such as HTML files, full-text documents, emails, and web posts. Text mining is concerned with the process of structuring input text to derive patterns in unstructured data to interpret and evaluate outputs $(\mathrm{He}, \mathrm{Zha}, \& \mathrm{Li}, 2013)$. The text mining process is relative with Knowledge Discovery in Databases (KDD) involving extracting high-level knowledge from hidden, large-sized data. Compared to traditional approaches, text mining could help researchers analyze thousands of records and clusters (Hsu, Hung, \& Ching, 2013). In the past, it has been very difficult to process this analysis without information technology. Nowadays, text mining decreases a large amount of labor and time. In this study, the authors follow the three-step process of text mining described in Miner et al. (2012)'s text mining methodology.

First, relevant documents are identified and collected manually or by automated techniques, such as web crawler/scraper. Then they are preprocessed (structured), which can also be done manually or automatically. The output, at this stage is, the input for the text analysis application.

Second, the text analysis software creates a two-dimensional term-document matrix (TDM), which presents the relationship between the terms and the documents. The relationship is measured by the frequency that the term occurred in a given document. At the beginning of this stage, researchers may apply filters of "stopwords" - to disregard words that are commonly found in documents (e.g. articles and prepositions, such as a, an, is, the) and "stemming" - to regard words with the same root as the same term. Thus, the number of distinct or unique terms is reduced and the number of particular terms may increase.

Third, the well-structured TDM is processed to find interesting patterns in the relationship of terms and documents. Extraction methods include: prediction, clustering, association, and trend analysis. In this study, the authors used Latent Semantic Analysis (LSA), which is an approach of optimizing the information retrieval query [24]. Recently, text mining software packages, such as SAS Text Miner, Statistica Text Mininer, and R, have been applied to LSA as an underlying technology for extracting topics. 


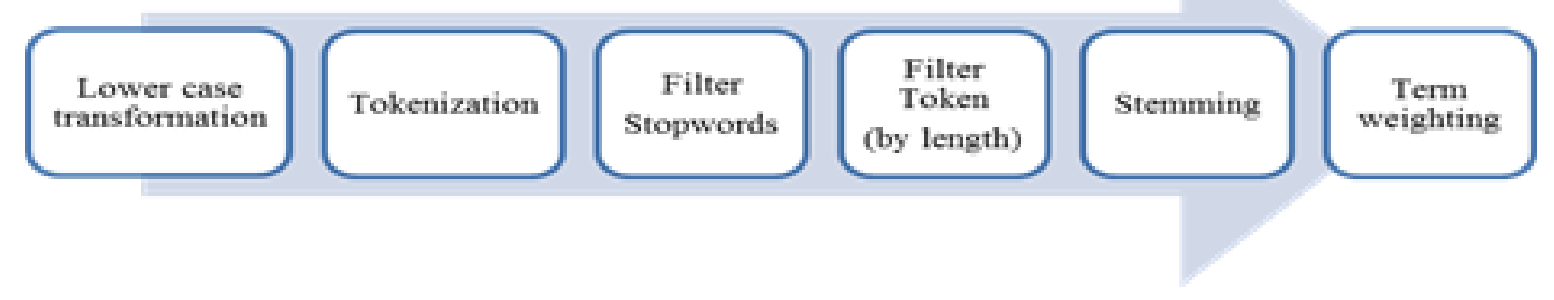

Fig. 1: Use "Figure" style here.

We adopted factor rotations steps similar to the study by Sidorova, A. Evangelopoulos, N. Valacich, J. S. Ramakrishnan (2008) and used the study by Evangelopoulos, Zhang, and Prybutok, (2012) as the procedure recommendation guideline. In the analysis phase, we applied the factor analysis approach to LSA, and generated two sets of high-loading terms and documents for each extracted factor. Then, we used these two sets of terms to label the factors.

\section{Empirical study: Data and Analysis}

The population in this study is large due to the high number of job advertisements. The authors used homogenous sampling because of the homogeneous characteristics in the group of interest. In this context, the group of interest is a sample of advertisements that share the following characteristics: 1) type -full-time position and human resource function, 2) place - posted from companies located in the U.S., and 3) date job advertisements that are active in LinkedIn.com during February 2014.

According to Harper's study (2012), the majority of job advertisement analysis used a sample size between 1 and 199. The criteria for collecting are as follows: 1) Positions are posted during a two-month period, February 1 to March 1, 2014; 2) Full-time positions; 3) Positions are entry-level; 4) Positions are listed under human resources functions; 5) Companies are located in the U.S.A.

Each job advertisement is coded directly onto a spreadsheet, which is used as a data set. A total of 300 job advertisements are identified for the U.S. The job advertisement attributes include job titles and job qualifications. Table 1 presents an example qualifications section from one of 300 collected human resource job announcements.

Table 1: Example of qualifications section

\section{Job title: Human Resources Administrator}

- Bachelor's degree or equivalent work experience.

- 3 to 5 years of generalist experience working in a manufacturing environment.

- Experience managing a high volume of open requisitions.

- Thorough knowledge of equal employment opportunity laws, and other government compliance regulations that affect job recruitment.

- Excellent interviewing, general communications and writing skills.

- Ability to multitask required.

- Excellent organizational skills.

- Computer skills utilizing Excel, Word and PowerPoint are required.

\subsection{Results}

After conducting text mining analysis, we identified four major factors, which are skills, education, experience, and ability, defining the key qualifications for human resource jobs. With the visual inspection of the eigenvalues on a screen plot, we initially selected four dimensions that explain core requirements for HR entry-level professionals. The results had 397 principal components.

Based on the examination of high-loading terms and documents in this case, we labelled extracted factors. Table 2 indicated the final labels presented by principal component order. Adopting the same threshold heuristic as the study of Sidorova et al. (2008), this paper assumed each statement to address, on average, one qualification factor. With the resulting terms threshold on the document loadings, we utilized a 
total count of high-loading documents to identify each factor. Table 3 indicated the result of each component loading after text mining analysis.

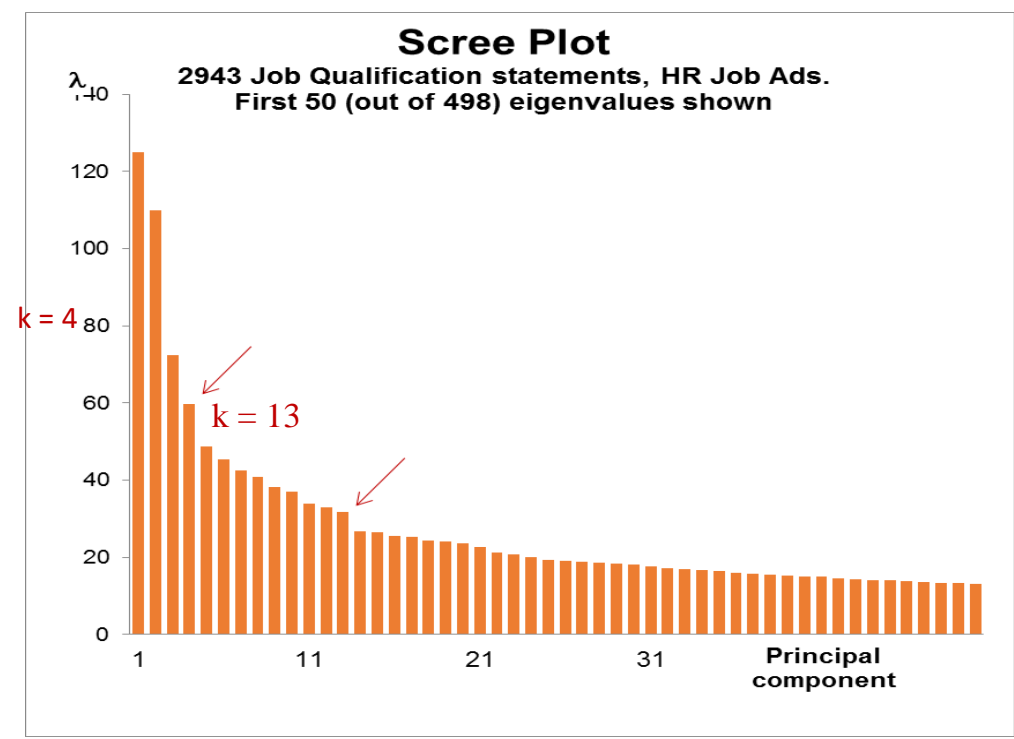

Fig. 2: Scree plot

Table 2: Extracted Four Major Qualification Themes

\begin{tabular}{ll}
\hline Factors & Count \\
\hline Skill & 607 \\
Education & 276 \\
Experience & 784 \\
Ability & 607 \\
\hline
\end{tabular}

To identify and prioritize the training and development needs for HR graduates; this study provides thirteen factors to suggest that HR graduates should consider thirteen themes. Table 3 indicates thirteen factors showing the HR professional qualifications which job seekers should consider. The candidates should master their competencies dealing with both human and business issues. With changing business conditions, HR professionals should have communication, leadership, and presentation skills to deal with human management issues. Moreover, based on the results of this study, entry-level HR candidates need to have at least a bachelor's degree, office software operation experience, and HR relative experience. HR recruiters also prefer certification and relative educational background.

Table 3: Extracted Thirteen Qualification Themes

\begin{tabular}{llll}
\hline No. & Factors & No. & Factors \\
\hline 1 & Educational degree & 8 & Project Management \\
2 & Communication & 9 & Presentation skills \\
3 & Experience & 10 & Analytical ability \\
4 & Leadership & 11 & Certification \\
5 & Office Software Operation & 12 & Accepting Traveling \\
6 & Team Work & 13 & Labor Law Knowledge \\
7 & Relative Educational Field & & \\
\hline
\end{tabular}

Emerging strategic competencies found that candidates should accumulate their relative HR experience. They need to possess presentation and office software operation skills to help them qualify HR entry level relative jobs. Additionally, employers proposed they need their candidates having leadership, analytical skills, organizing teamwork, and communication ability. HR relative certifications, accepting traveling, and labor 
law knowledge could help candidates effectively compete for these jobs. Finally, educational level focuses on a bachelor's degree.

\subsection{Discussion}

In this section, the basic competencies of early career HR professionals are discussed. Based on our results, the major competencies for entry-level human resources professionals in the U.S. are grouped into four themes, which are skills, appropriate education, relevant experience, and abilities. According to the results presented in Table 2, communication, writing, verbal, and interpersonal skills are also among the skills highly ranked by employers. A bachelor's degree would be a necessary achievement considered by employers for entry-level human resources professionals. Particularly, human resource management and business are considered an appropriate education requirement for this career. Regarding professional experience, employers consider candidates who have experience in management and the human resource field would be preferred for handling the responsibility of the position. HR candidates should also have teamwork, organization, and management abilities to satisfy the requirements of the job.

Experience establishes one of keystones of professional success in human resource management. Essentially, companies are looking for candidates experienced with human resource management. Dealing with human relations, communication, and teamwork would be challenged because of this dynamic complex. Therefore, employers would prefer to look for those candidates with some experience in human resource management. However, general traditional courses have some limitations for effectively increasing student experience with real world situations. The training and educational programs should offer internship opportunities or establish work experience requirements for degree plans. Moreover, students should be encouraged to contact several industries or functional areas, such as information technology, finance, marketing, or logistics. Hence, they could gain more experience in dealing with teamwork and communication problems in several industries.

Interpersonal skills are the most desired skills in human resource management entry level jobs. Communication skills, such as verbal and written communication, are considered the most desired qualifications. Based on the result of analysis indicates that employers recognize that human resource management employees need to effectively communicate with others in a short time [27]. Regarding abilities, teamwork would be one of vital factors for human resource management jobs. A candidate should have managerial, project management and organizing abilities. For this reason, degree programs or training programs related to the human resource management need to consider teamwork as an important critical factor in designing teaching or training content. Foundational courses that help build communication skills, such as courses in technical writing, public speaking, negotiations, leadership, and organizational behavior, would be effective and efficient in improving students' or trainees' communication abilities for entering human resource management job markets. Furthermore, educational organizations should encourage their human resource management students or trainees to include communication and leadership related training programs during their learning process. Moreover, the courses or training programs should provide more opportunities to practice communication skills and teamwork abilities. For instance, instruction design could include team projects, written reports, and oral presentations. Instruction designers can provide their students and trainees the ability to improve those skills by organizing course content, designing challenging projects, and practicing teamwork activities.

\section{Conclusion}

This paper adopted a demand-centric approach to recognize core human resource entry level job competencies. Using text mining to analyze job ads on LinkedIn, we identified four components of professional success in human resource management, which include skills, education, experience, and ability. We, furthermore, observed specific skills, educational level, experience, and types of abilities that are significant to getting a job in human resource management. The result suggests that a bachelor's program in business administration, management and human resource are considered by employers as a suitable requirement of degrees for human resource careers. Experience plays one of critical successful factors in human resources; and educational organizations should encourage and help their students gain the 
appropriate and focused experience. In a future study, HRCS could be a consideration for deeply exploring HR competencies necessary; moreover, future research could update and review HR program competencies through examining the latest trends.

\section{References}

[1] K. J.Janzen, B.Perry, and M.Edwards. Aligning the quantum perspective of learning to instructional design: Exploring the seven definitive questions. Open Distance Learn.. 2011, 12, (7): 56-73.

[2] M. A.Robinson, P. R.Sparrow, C.Clegg, and K.Birdi. Forecasting future competency requirements: A three-phase methodology. 2007, 36(1): 65-90.

[3] M.Koç, M.Demirbilek, and E.Yılmaz İnce. A needs assessment for academicians' professional development. TeEğitim VBilim. 2015, 40(177): 297-311.

[4] J.Hung. Trends of e-learning research from 2000 to 2008: Use of text mining and bibliometrics. Br. J. Educ. Technol..2012, 43(1): 5-16.

[5] S.Ganesh. Text Mining in analyzing the presentation of educational trainers. Int. J. Comput. 2013, 66(7): 38-44.

[6] M.Abdous and W.He. Using text mining to uncover students' technology-related problems in live video straming. Br. J. Educ. Technol. 2011, 42(1): 40-49.

[7] P.Boxall, J.Purcell, and P.Wright. Human resource management scope, analysis, and significance. in The Oxford handbook of human resource management. In: P.Boxall, J.Purcell, and P.Wright (eds.). New York: Oxford University Press, 2007, pp. 1-18.

[8] T.Mahoney and J.Deckop. Evolution of concept and practice in personnel administration/human resource management (PA/HRM). J. Manage. 1986, 12: 223-241.

[9] J.Delery and D.Doty. Modes of theorizing in strategic human resource management: Tests of universalistic, contingency, and configurational performance predictions. Acad. Manag. J.. 1996, 39(4): 802-835.

[10] V.Pucik and J. L.Barsoux. The Global Challenge: Frameworks For Inter National Human Resource Management. New York: McGraw Hill, 2002.

[11] P. J.Dowling and D. E.Welch. International Human Resource Management: Managing People In A Multinational Context. London, UK: Thomson, 2004.

[12] J.Pfeffer and C. T.Fong. The end of business schools? Less success than meets the eye. Acad. Manag. Learn. Educ. 2002, 1: 78-95.

[13] J. L.Alssid and P.Shields. College in the call center. American Society for Training \& Development. 2014, 51-54.

[14] R.Harper, "The collection and analysis of job advertisements: a review of research methodology.," Libr. Inf. Res., vol. 36, no. 112, pp. 29-54, 2012.

[15] L.Gray. New Zealand HRD practitioner competencies: Application of the ASTD competency model. Int. J. Hum. Resour. Manag. 1999, 10(6): 1046-1059.

[16] D. H.Wenger and L. C.Owens. Help wanted 2010. Journal. Mass Commun. Educ. 2012, 67(1): 9-25.

[17] H.Hämäläinen, J.Porras, and J.Ikonen. A tool for visualizing skill requirements in ICT job advertisements. Proc. of 7th E-learning Conference, e-Learning'11, 2011, pp. 254-259.

[18] S.Surakka. Analysis of technical skills in job advertisements targeted at software developers. Informatics Educ. Int. J. 2005, 35(1): 101-122.

[19] K. S.Croneis and P.Henderson. Electronic and digital librarian positions: A content analysis of announcements from 1990 through 2000. J. Acad. Librariansh.2002, 28(4): 232-237.

[20] S.Ahmed. Desired competencies and job duties of non-profit CEOs in relation to the current challenges: Through the lens of CEOs' job advertisements. J. Manag. Dev. 2005, 24(10): 913-928.

[21] W.He, S.Zha, and L.Li. Social media competitive analysis and text mining: A case study in the pizza industry. Int. J. Inf. Manage. 2013, 33: 464-472.

[22] Y. C.Hsu, J. L.Hung, and Y. H.Ching. Trends of educational technology research: More than a decade of international research in six SSCI-indexed refereed journals. Educ. Technol. Res. Dev. 2013, 61(4): 685-705. 
[23] G.Miner, J.Elder, A.Fast, T.Hill, R.Nisbet, and D.Delen. Practical Text Mining And Statistical Analysis For NonStructured Text Data Applications. Waltham, WA: Academic Press, 2012.

[24] S.Deerwester, S. T.Dumais, G.Furnas, T. K.Landauer, and R.Harshman. Indexing by latent semantic analysis. $J$. Am. Soc. Inf. Sci. 1990, 41(6): 391-407.

[25] A.Sidorova, N.Evangelopoulos, J. S.Valacich, and T.Ramakrishnan. Uncovering the intellectual core of the information systems discipline. MIS Q. 2008, 32(3): 467-482.

[26] N.Evangelopoulos, X.Zhang, and V.Prybutok. Latent semantic analysis: Five methodological recommendations. Eur. J. Inf. Syst. 2012, 21(1): 70-86.

[27] B. L.Reece and R.Brandt, Effective Human Relations, Tenth. Boston, MA: Houghton Mifflin Company, 2013. 